\title{
Correlation between the levels of serum cystatin $C$ and substance $P$ in peripheral blood in diabetes mellitus patients complicated with hypertension
}

\author{
WEI ZHU ${ }^{1}$, XUELIAN GONG ${ }^{2}, \mathrm{CHAO} \mathrm{LUO}^{3}$ and JING LU ${ }^{4}$ \\ ${ }^{1}$ Department of Clinical Laboratory, Baoji Central Hospital, Baoji, Shaanxi 721008; \\ ${ }^{2}$ Department of Internal Medicine, Xi'an No. 5 Hospital, Xi'an, Shaanxi 710000; ${ }^{3}$ Basic Medical College, \\ Hubei University of Science and Technology, Xianning, Hubei 437100; ${ }^{4}$ Department of Geriatrics, \\ No. 215 Hospital of Shaanxi Nuclear Industry, Xianyang, Shaanxi 712000, P.R. China
}

Received September 1, 2017; Accepted May 23, 2018

DOI: $10.3892 /$ etm.2018.6285

\begin{abstract}
Correlation between the serum cystatin $\mathrm{C}$ and substance $\mathrm{P}$ in peripheral blood of diabetes mellitus patients complicated with hypertension was investigated. Diabetes mellitus patients with or without hypertension were selected in No. 215 Hospital of Shaanxi Nuclear Industry from December 2015 to February 2017. There were 60 patients with only hypertension (hypertension control group), 60 patients with only diabetes mellitus (diabetes mellitus control group) and 60 patients with diabetes mellitus combined with hypertension (observation group). Levels of serum cystatin C and substance $\mathrm{P}$ in peripheral blood were measured via immunoturbidimetry and enzyme-linked immunosorbent assay, respectively, and the correlation with hypertension was analyzed. The average level of serum cystatin $\mathrm{C}$ in the observation group was higher than that of the two control groups $(\mathrm{P}<0.05)$. The level of substance $\mathrm{P}$ in peripheral blood of the observation group was lower than that of the diabetic control group $(\mathrm{P}<0.05)$. The levels of serum cystatin $\mathrm{C}$ in patients with grade III hypertension in observation group were higher than those in grades II and I, and the levels of substance $\mathrm{P}$ in peripheral blood of patients with grade III hypertension in observation group were lower than those in grades II and I. Systolic pressure of patients in observation group was significantly positively correlated with level of serum cystatin $\mathrm{C}$, but significantly negatively correlated with level of substance $\mathrm{P}$ in peripheral blood $(\mathrm{P}<0.05)$. Compared with the diabetes mellitus patients, level of serum cystatin $C$ was higher, and level of substance $\mathrm{P}$ peripheral blood was lower in diabetes
\end{abstract}

Correspondence to: Dr Jing Lu, Department of Geriatrics, No. 215 Hospital of Shaanxi Nuclear Industry, 35 Weiyangxi Road, Xianyang, Shaanxi 712000, P.R. China

E-mail: byu2jn@163.com

Key words: diabetes mellitus, hypertension, serum cystatin C, substance $\mathrm{P}$ in peripheral blood mellitus patients complicated with hypertension. In diabetes mellitus patients, blood pressure was positively correlated with serum cystatin C level, and negatively correlated with substance $\mathrm{P}$ level in peripheral blood.

\section{Introduction}

Increases in blood pressure are always accompanied with the elevated risks in cardiovascular diseases, such as myocardial infarction, heart failure and stroke. Aging of population in China increases the risk of hypertension and its cardiovascular (1). In diabetes mellitus (DM) patients, risk of cardiovascular complications, coronary artery disease (CAD), cerebral stroke and peripheral arterial diseases are two to four times higher than that in people without DM $(2,3)$. $\mathrm{DM}$ is always accompanied with hypertension, and, thus, DM patients complicated with hypertension usually suffer from an increased risk of cardiovascular complications (4). Corresponding studies have reported that during the follow-up period of DM patients without cardiovascular diseases, the risk of cardiovascular diseases is almost equivalent to non-DM patients with history of cardiovascular diseases $(5,6)$. Serum cystatin $\mathrm{C}$ is a kind of kidney-secreted enzyme that is widely distributed in the body, and can reflect the filtrating function of glomerulus (7). Diabetes and hypertension often affect kidneys. However, there is no report on the serum levels of cystatin $\mathrm{C}$ in patients with diabetes mellitus combined with hypertension. We hypothesized that serum cystatin $\mathrm{C}$ may have some predictive value in detecting renal damage in patients with hypertension or diabetes without clinical renal impairments (proteinuria and renal insufficiency), whereas those with diabetes mellitus combined with hypertension are more likely to have renal damage in the early stage, and serum cystatin $\mathrm{C}$ levels may be higher in these patients than in patients with only diabetes. Substance $\mathrm{P}$ refers to a kind of neuropeptide widely distributed in fine nerve fibers. When the nerve is stimulated, substance $\mathrm{P}$ can be released through the central end and peripheral end, and bind to neurokinin-1 receptor (NK1) to exert the physiological function. Peripheral neuropathy is one of the common complications of DM. There 
is usually an increase in substance $\mathrm{P}$ in patients with diabetes mellitus combined peripheral neuropathy. However, there is no report on the effect of hypertension on substance $\mathrm{P}$ in patients with diabetes mellitus. In order to measure the concentration of serum cystatin $C$ and substance $P$ in peripheral blood of DM patients with hypertension, DM patients, hypertension patients and DM patients with hypertension were selected from December 2015 to February 2017. There were 60 patients with only DM (control group), 60 patients with only hypertension (control group) and $60 \mathrm{DM}$ patients with hypertension (observation group). We measured levels of serum cystatin $\mathrm{C}$ and substance $\mathrm{P}$ in peripheral blood of all the patients.

\section{Patients and methods}

General data of patients. DM patients with or without hypertension who were admitted to No. 215 Hospital of Shaanxi Nuclear Industry (Xianyang, China) between December 2015 and February 2017 were enrolled in this study. Inclusion criteria: i) Patients aged between 40 and 80 years; ii) patients met the Diagnostic Criteria of Diabetes Mellitus (2010 edition, American Diabetes Association): i) glycosylated hemoglobin $(\mathrm{HbA} 1 \mathrm{c}) \geq 6.5 \%$; ii) fasting plasma glucose $(\mathrm{FPG}) \geq 7.0 \mathrm{mmol} / 1$ (patients fasted for $8 \mathrm{~h}$ ); iii) $2 \mathrm{~h}$ plasma glucose in oral glucose tolerance test $\geq 11.1 \mathrm{mmol} / \mathrm{l}$; iv) random blood sugar $\geq 11.1 \mathrm{mmol} / 1$ for patients with the typical symptoms or crisis of high glucose; c) patients whose systolic pressure reached or exceeded $21.3 \mathrm{kPa}(160 \mathrm{mmHg})$ and diastolic pressure reached or exceeded $12.7 \mathrm{kPa}(95 \mathrm{mmHg})$. Hypertension classification was based on the $1999 \mathrm{WHO} / \mathrm{ISH}$ guidelines for the treatment of hypertension (8). Exclusion criteria: a) patients with type I DM; b) patients complicated with renal insufficiency, hematuresis or proteinuria; c) patients complicated with severe infections; d) patients complicated with tumors. Among these patients, we selected $60 \mathrm{DM}$ patients complicated with hypertension as observation group. Those patients included 26 males and 35 females and the age ranged from 46 to 80 years, with an average of $65.3 \pm 5.6$ years. For hypertension grading, there were 16 with hypertension of grade I, 18 of grade II and 26 of grade III. Sixty patients with simple diabetes (28 males and 32 females, aged 48-82 years, mean age 66.2 \pm 5.2 years and simple hypertension in 60 patients (30 males and 30 females, aged 44-79 years, mean age $65.8 \pm 6.1$ years as the control group in this study. There were 28 males and 32 females, and the age ranged from 48-82 years with an average of 66.2 \pm 5.2 years. No statistical significance was found in comparisons of age and sex among groups. This study was approved by the Ethics Committee of Baoji Central Hospital (Baoji, China), and all the patients or their family signed the informed consent.

Detection of serum cystatin $C$. Fasting venous $(3 \mathrm{ml})$ blood was extracted from each patient in the morning to detect serum cystatin $\mathrm{C}$ by particle reinforcement particle-enhanced turbidimetric immunoassay (PETIA) using Olympus AU 2700 automatic biochemical analyzer (Ningbo Purebio Biotechnology Co., Ltd., Ningbo, China) in accordance with the instructions of kit and apparatus.

Detection of substance P level in peripheral blood. Enzymelinked immunosorbent assay (ELISA) was performed using an ELISA kit (R\&D Systems, Inc., Minneapolis, MN, USA) to detect substance $\mathrm{P}$ in peripheral blood of each patient in strict accordance with the instruction of the kit. Elbow venous blood (3 ml) was collected, followed by centrifugation at 2,500 $\mathrm{x} g$ at $4^{\circ} \mathrm{C}$ for $15 \mathrm{~min}$, and the separated plasma was stored at $-70^{\circ} \mathrm{C}$ before use. OD values at $492 \mathrm{~nm}$ were detected to calculate the content of substance $\mathrm{P}$ in peripheral blood.

Statistical analysis. SPSS 22.0 (IBM Corp., Armonk, NY, USA) software was used. All measurement data were expressed as mean \pm standard deviation, and independent sample t-test. Comparison between groups was done using one-way ANOVA test followed by post hoc test (Least Significant Difference). Enumeration data were expressed as No. (case) or percentage, and Chi-square test was performed for intergroup comparisons. Spearman's correlation analysis was adopted for correlation analyses. $\mathrm{P}<0.05$ was considered to indicate a statistically significant difference.

\section{Results}

Comparison of the levels of serum cystatin $C$ and substance $P$ in peripheral blood of patients in three groups. There was no significant difference in serum cystatin $\mathrm{C}$ and peripheral blood substance $\mathrm{P}$ levels between diabetes control group and hypertension control group. Average level of serum cystatin C was significantly higher in observation group than in the two control groups. The level of substance $\mathrm{P}$ in peripheral blood in the observation group was lower than that in the diabetic control group $(\mathrm{P}<0.05)$, but there was no difference between the observation group and the hypertension control group $(\mathrm{P}>0.05)$. Average levels of serum cystatin $\mathrm{C}$ and substance $P$ in peripheral blood of observation group were $1.18 \pm 0.53 \mathrm{mg} / 1$ and $112.65 \pm 28.37 \mathrm{ng} / 1$, respectively, and those in diabetes control group were $1.04 \pm 0.48 \mathrm{mg} / \mathrm{l}$ and $145.28 \pm 27.06 \mathrm{ng} / 1$, respectively. Significant differences were found between two groups $(\mathrm{t}=2.185, \mathrm{t}=1.028, \mathrm{P}<0.05)$ (Table I).

Comparison of the levels of serum cystatin $C$ and substance $P$ in peripheral blood in patients with different grades of hypertension in observation group. There was no statistically significant difference between the distributions of patients with grade I, II and III hypertension in the hypertension-only control and the observation groups $(\mathrm{P}>0.05)$. In observation group, level of serum cystatin $\mathrm{C}$ was significantly higher, while substance $\mathrm{P}$ level in peripheral blood was significantly lower in patients with grade III hypertension than those in the patients with grade I or II hypertension $(\mathrm{P}<0.05)$. Comparisons of the serum cystatin $\mathrm{C}$ level and substance $\mathrm{P}$ level in peripheral blood between patients with grade I and II hypertension showed no statistical significance $(\mathrm{P}>0.05)$. In control group, serum levels of cystatin $\mathrm{C}$ in patients with level III hypertension were significantly higher than those in patients with level II and I, while no significant difference was found between level II and $\mathrm{I}$ in serum levels of cystatin $\mathrm{C}$ and levels of substance $\mathrm{P}$ in peripheral blood $(\mathrm{P}>0.05)$. No significant differences were found between patients in observation group and control group with the same level of hypertension $(\mathrm{P}>0.05)$ (Tables II and III). 
Table I. Comparison of the levels of serum cystatin $\mathrm{C}$ and substance $\mathrm{P}$ in peripheral blood of patients in two groups (mean $\pm \mathrm{SD}$ ).

\begin{tabular}{lccc}
\hline Groups & No. & $\begin{array}{c}\text { Serum cystatin } \\
\text { C (mg/l) }\end{array}$ & $\begin{array}{c}\text { Substance P in } \\
\text { peripheral blood (ng/l) }\end{array}$ \\
\hline Observation & 60 & $1.18 \pm 0.53$ & $112.65 \pm 28.37$ \\
Diabetes control & 60 & $1.04 \pm 0.48$ & $145.28 \pm 27.06$ \\
Hypertension control & 60 & $0.98 \pm 0.38$ & $113.08 \pm 27.13$ \\
${ }^{a}$ t value & & 2.185 & 1.028 \\
bt value & & 2.062 & 0.978 \\
${ }^{a}$ P value & & $<0.05$ & $<0.05$ \\
${ }^{b}$ P value & & $<0.05$ & $>0.05$ \\
\hline
\end{tabular}

${ }^{a} \mathrm{t}$ and ${ }^{\mathrm{a}} \mathrm{P}<0.05$ vs. diabetes control group, ${ }^{\mathrm{b}} \mathrm{t}$ and ${ }^{\mathrm{b}} \mathrm{P}<0.05$ vs. hypertension control group. SD, standard deviation.

Table II. Comparison of serum cystatin C levels between patients in observation group and hypertension-only control group with different levels of hypertension (mean $\pm \mathrm{SD})$.

\begin{tabular}{|c|c|c|c|c|c|}
\hline \multirow[b]{2}{*}{ Levels } & \multicolumn{2}{|c|}{ Observation } & \multirow[b]{2}{*}{ Cases } & \multicolumn{2}{|c|}{ Hypertension-only control } \\
\hline & Cases & Serum cystatin $C(\mathrm{mg} / \mathrm{l})$ & & Serum cystatin C (mg/l) & $\mathrm{P}$-value \\
\hline III & 28 & $1.24 \pm 0.34$ & 26 & $1.38 \pm 0.64$ & $>0.05$ \\
\hline II & 17 & $1.11 \pm 0.54^{\mathrm{a}}$ & 18 & $1.17 \pm 0.51^{\mathrm{b}}$ & $>0.05$ \\
\hline I & 15 & $1.01 \pm 0.44^{\mathrm{a}}$ & 16 & $1.06 \pm 0.43^{b}$ & $>0.05$ \\
\hline F-value & & 8.889 & & 9.024 & \\
\hline P-value & & $<0.05$ & & $<0.05$ & \\
\hline
\end{tabular}

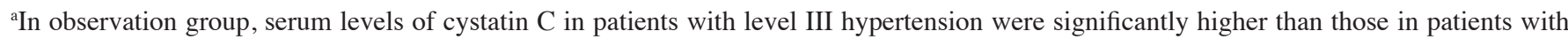
level II and I; ${ }^{b}$ In hypertension-only control, serum levels of cystatin C in patients with level III hypertension were significantly higher than those in patients with level II and I.

Table III. Comparison of levels of P substance in peripheral blood between patients in observation group and hypertension-only control with different levels of hypertension (mean $\pm \mathrm{SD}$ ).

\begin{tabular}{|c|c|c|c|c|c|}
\hline \multirow[b]{2}{*}{ Levels } & \multicolumn{2}{|c|}{ Observation } & \multirow[b]{2}{*}{ Cases } & \multicolumn{2}{|c|}{ Hypertension-only control } \\
\hline & Cases & $\begin{array}{c}\text { P substance in } \\
\text { peripheral blood }(n g / l)\end{array}$ & & $\begin{array}{c}\text { P substance in } \\
\text { peripheral blood (ng/l) }\end{array}$ & P-value \\
\hline III & 28 & $102.93 \pm 26.67$ & 26 & $100.43 \pm 25.67$ & $>0.05$ \\
\hline II & 17 & $117.28 \pm 27.95^{\mathrm{a}}$ & 18 & $112.25 \pm 26.91^{\mathrm{b}}$ & $>0.05$ \\
\hline I & 15 & $125.57 \pm 29.31^{\mathrm{a}}$ & 16 & $126.57 \pm 27.31^{\mathrm{b}}$ & $>0.05$ \\
\hline F value & & 10.326 & & 11.453 & \\
\hline P-value & & $<0.05$ & & $<0.05$ & \\
\hline
\end{tabular}

an observation group, levels of $\mathrm{P}$ substance in peripheral blood in patients with level III hypertension were significantly lower than those in patients with level II and I; 'In hypertension-only control, levels of P substance in peripheral blood in patients with level III hypertension were significantly lower than those in patients with level II and I.

Correlation of the systolic pressure with the levels of serum cystatin $C$ and substance $P$ in peripheral blood of patients in the observation group. Correlation analysis showed that systolic pressure of patients in the observation group was significantly positively correlated with level of serum cystatin $\mathrm{C}(\mathrm{r}=0.437, \mathrm{P}<0.05)$, but significantly negatively correlated with the level of substance $\mathrm{P}$ in peripheral blood $(\mathrm{r}=-0405, \mathrm{P}<0.05)($ Fig. 1). 

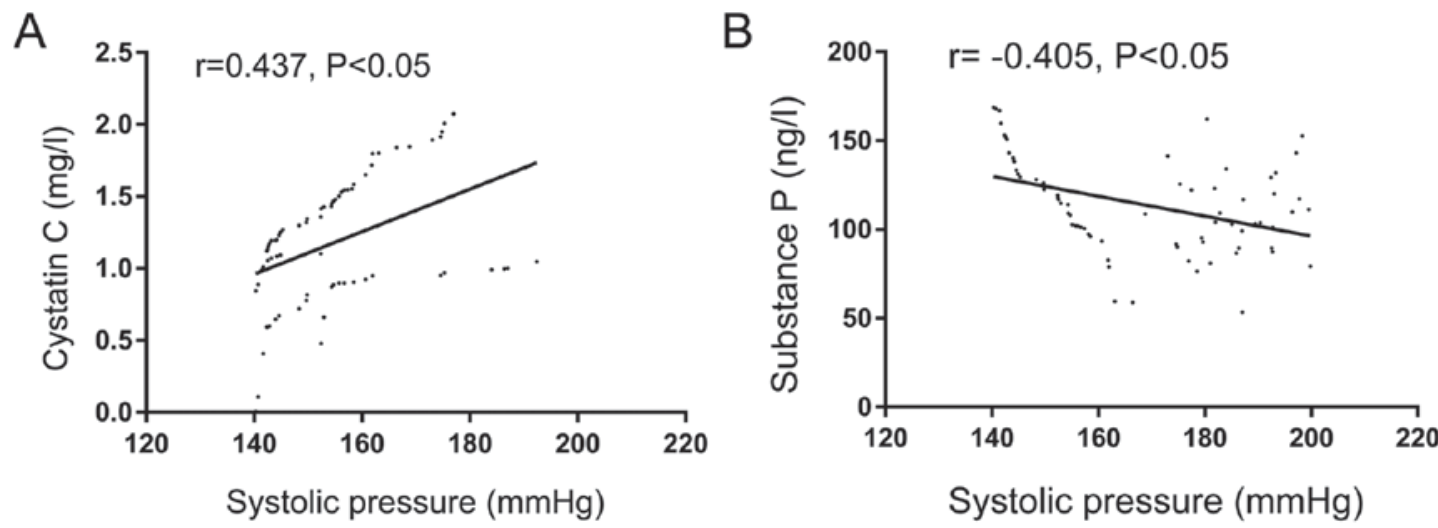

Figure 1. Correlation analysis of the systolic pressure with the levels of serum cystatin $\mathrm{C}$ and substance $\mathrm{P}$ in peripheral blood of patients in the observation group. A) A positive correlation was observed between systolic pressure and serum cystatin $\mathrm{C}(\mathrm{r}=0.437, \mathrm{P}<0.05)$; $\mathrm{B})$ a negative correlation was detected between systolic pressure and the level of substance $\mathrm{P}(\mathrm{r}=-0.405, \mathrm{P}<0.05)$.

\section{Discussion}

Type II DM is a kind of metabolic disease with chronic hyperglycemia, in which insufficient secretion of insulin or insulin-resistance leads to the metabolic disturbance of nutrients, such as glucose, fat and protein. Long-term hyperglycemia and metabolic disturbance usually result in damage to multiple organs, including eyes, kidney, nerve, heart and vessels $(9,10)$. However, in DM patients, the risk of cardiovascular complications is equivalent to that of patients with CAD, and, thus, similar treatment methods should be adopted to improve the prognosis of cardiovascular diseases $(11,12)$. DM is usually accompanied with hypertension, which is a key risk factor for cardiovascular complications in DM patients $(13,14)$. Previous studies reported that approximately $20-60 \%$ of DM patients were also suffering hypertension, and $25-50 \%$ of hypertension patients were combined with DM, and patients with DM and hypertension were usually more susceptible to the cardiovascular diseases $(15,16)$. Rodrigues et al reported that in DM patients complicated with hypertension, risk of cardiovascular complications was almost twice of that in people without DM or hypertension (17). In this study, we compared the levels of serum cystatin $\mathrm{C}$ and substance $\mathrm{P}$ in peripheral blood between the DM patients and DM patients combined with hypertension for the first time, and our results suggested the clinical significance of serum cystatin $\mathrm{C}$ and substance $\mathrm{P}$ levels in DM and hypertension.

Serum cystatin C, also known as $\gamma$-trace protein, is a cysteine proteinase inhibitor widely distributed in tissues and body fluid (18). Cystatin C in blood can only be filtrated and eradicated by glomerulus, and, thus, can indicate the changes in glomerular filtration rate (GFR) (19). Previous studies have shown that serum cystatin $\mathrm{C}$ is conducive to the evaluation of GFR, and can increase the detection rate of renal function damage in early stage of DM (20-22). Patients complicated with renal insufficiency, hematuresis or proteinuria were excluded from this study, and we found that average level of serum cystatin $\mathrm{C}$ in DM patients with hypertension was significantly higher than that in control group, suggesting that serum cystatin $\mathrm{C}$ has a significant predictive value for hypertension. Furthermore, we found that serum level of cystatin $\mathrm{C}$ was higher in DM patients with grade III hypertension than in patients with grade I or II, indicating that serum cystatin C level is correlated with hypertension. Silva-E-Oliveira et al (23) found that level of serum cystatin $\mathrm{C}$ is correlated with the flow-mediated vasodilation. Bhavsar et al (24) also found that serum cystatin $\mathrm{C}$ in patients with pregnancy-induced hypertension syndrome was significantly higher than that in normal control group. Compared with the patients with only DM, level of serum cystatin C in DM patients complicated with hypertension was significantly increased, suggesting that those patients were more susceptible to renal damage and refractory hypertension.

As a kind of brain-gut peptide, substance $\mathrm{P}$ is not only the neurotransmitter or neuromodulator, but also a kind of key chemokine in modulating the immune system and endocrine system (25). Menzies et al (26) found that complications of DM, such as CAD, neuropathic pain or gastrointestinal dysfunction, were correlated with content of substance $\mathrm{P}$ in peripheral blood. Grover et al (27) also reported that in type II DM patients, content of substance $\mathrm{P}$ level in plasma was significantly lower than that in healthy people, and a much lower level was found in the DM patients combined with gastroesophageal reflux. Iwasaki et al (28) found that in DM patients, decrease in substance $\mathrm{P}$ level in peripheral blood may be associated with the onset of diabetes gastroparesis. In addition, decreased level of substance $P$ in peripheral blood contributes to the significant increase in cytokines secreted by immune competent cells and improvement in bone metabolism. In this study, compared with DM patients, substance P level in peripheral blood in DM patients combined with hypertension was significantly reduced, which in turn affect the major organs of patients, including heart and lungs. Correlation analysis also revealed that systolic pressure of DM patients complicated with hypertension was significantly negatively correlated with substance P level in peripheral blood $(\mathrm{P}<0.05)$. Thus, compared with $\mathrm{DM}$ patients, substance $\mathrm{P}$ level in peripheral blood was relatively lower, and blood pressure was negatively correlated with the substance $\mathrm{P}$ level in peripheral blood of DM patients complicated with hypertension.

In conclusion, we detected the levels of serum cystatin $\mathrm{C}$ and substance $\mathrm{P}$ in peripheral blood of DM patients complicated with hypertension, and found that content of serum cystatin $\mathrm{C}$ was relatively high and level of substance $\mathrm{P}$ in peripheral blood 
was relatively low in DM patients with hypertension, and blood pressure was positively correlated with the serum cystatin $\mathrm{C}$ level and negatively correlated with the substance $\mathrm{P}$ level in peripheral blood in these patients. Our findings provided references for further investigations on the mechanism.

\section{Acknowledgements}

Not applicable.

\section{Funding}

No funding was received.

\section{Availability of data and materials}

The datasets used and/or analyzed during the present study are available from the corresponding author on reasonable request.

\section{Authors' contributions}

WZ conceived and designed the study, and drafted the manuscript. XG, CL and JL collected, analyzed and interpreted the patient data, and revised the manuscript critically for important intellectual content. All authors read and approved the final manuscript.

\section{Ethics approval and consent to participate}

The study was approved by the Ethics Committee of Baoji Central Hospital (Baoji, China). Signed informed consents were obtained from the patients or the guardians.

\section{Patient consent for publication}

Not applicable.

\section{Competing interests}

The authors declare that they have no competing interests.

\section{References}

1. Ranpise N, Jamkar P and Langote H: Do fixed dose combinations play an important role in the management of coexistent type two diabetes mellitus and hypertension? Ind J Pharm Edu Res 49: 190-199, 2015. https://pdfs.semanticscholar.org/bb29/ cc69f43e2026d0e6b8e1b107782de8c0b51b.pdf.

2. Hill MD: Stroke and diabetes mellitus. Handb Clin Neurol 126 : 167-174, 2014

3. Janghorbani M and Amini M: Progression from optimal blood glucose and pre-diabetes to type 2 diabetes in a high risk population with or without hypertension in Isfahan, Iran. Diabetes Res Clin Pract 108: 414-422, 2015.

4. Guo K, Zhou Z, Jiang Y, Li W and Li Y: Meta-analysis of prospective studies on the effects of nut consumption on hypertension and type 2 diabetes mellitus. J Diabetes 7: 202-212, 2015.

5. Lan J, Zhao Y, Dong F, Yan Z, Zheng W, Fan J and Sun G: Metaanalysis of the effect and safety of berberine in the treatment of type 2 diabetes mellitus, hyperlipemia and hypertension. $\mathbf{J}$ Ethnopharmacol 161: 69-81, 2015.

6. Danquah I, Dobrucky CL, Frank LK, Henze A, Amoako YA, Bedu-Addo G, Raila J, Schulze MB, Mockenhaupt FP and Schweigert FJ: Vitamin A: Potential misclassification of vitamin A status among patients with type 2 diabetes and hypertension in urban Ghana. Am J Clin Nutr 102: 207-214, 2015.
7. Chung JO, Cho DH, Chung DJ and Chung MY: Serum cystatin C levels are positively associated with cardiovascular autonomic neuropathy in patients with type 2 diabetes. Exp Clin Endocrinol Diabetes 123: 627-631, 2015.

8. Kjeldsen SE, Farsang C, Sleigh P, Mancia G; World Health Organization; International Society of Hypertension: 1999 WHO/ISH hypertension guidelines - highlights and ESH update. J Hypertens 19: 2285-2288, 2001.

9. Li N, Beck T, Chen J, Biermann C, Guo L, Sun H, Gao F and Liu C: Assessment of thoracic aortic elasticity: A preliminary study using electrocardiographically gated dual-source CT. Eur Radiol 21: 1564-1572, 2011.

10. Edelman D, Dolor RJ, Coffman CJ, Pereira KC, Granger BB, Lindquist JH, Neary AM, Harris AJ and Bosworth HB: Nurse-led behavioral management of diabetes and hypertension in community practices: A randomized trial. J Gen Intern Med 30: 626-633, 2015.

11. Kamoi K: Usefulness of morning home blood pressure measurements in patients with type 2 diabetes mellitus: Results of a 10-year, prospective, longitudinal study. Clin Exp Hypertens 37: 122-127, 2015.

12. Hara Y, Kawagishi N, Nakanishi W, Tokodai K, Nakanishi C, Miyagi S and Ohuchi N: Prevalence and risk factors of obesity, hypertension, dyslipidemia and diabetes mellitus before and after adult living donor liver transplantation. Hepatol Res 45: 764-770, 2015.

13. Liang S, Cai GY and Chen XM: Clinical and pathological factors associated with progression of diabetic nephropathy. Nephrology (Carlton) 22 (Suppl 4): 14-19, 2017.

14. Mozafari M, Nekooeian AA, Mashghoolozekr E and Panjeshahin MR: The cardioprotective effects of resveratrol in rats with simultaneous type 2 diabetes and renal hypertension. Nat Prod Commun 10: 335-338, 2015.

15. Zhou J, Liu C, Shan P, Zhou Y, Xu E and Ji Y: Prevalence and distinguishing features of masked hypertension in type 2 diabetic patients. J Diabetes Complications 27: 82-86, 2013.

16. Ito WD, Lund N, Sager H, Becker W and Wenzel U: Differential impact of diabetes mellitus type II and arterial hypertension on collateral artery growth and concomitant macrophage accumulation. Vasa 44: 31-41, 2015

17. Rodrigues KF, Pietrani NT, Bosco AA, Campos FMF, Sandrim VC and Gomes KB: IL-6, TNF- $\alpha$, and IL-10 levels/ polymorphisms and their association with type 2 diabetes mellitus and obesity in Brazilian individuals. Arch Endocrinol Metab 61: 438-446, 2017.

18. Matsushita K, Sang Y, Ballew SH, Astor BC, Hoogeveen RC, Solomon SD, Ballantyne CM, Woodward M and Coresh J: Cardiac and kidney markers for cardiovascular prediction in individuals with chronic kidney disease: The Atherosclerosis Risk in Communities study. Arterioscler Thromb Vasc Biol 34: 1770-1777, 2014.

19. Yan PJ, Xu Y, Wan Q, Feng J, Li H, Gao CL, Yang J, Zhong HH and Zhang ZH: Decreased plasma neuregulin 4 concentration is associated with increased high-sensitivity $\mathrm{C}$-reactive protein in newly diagnosed type 2 diabetes mellitus patients: A crosssectional study. Acta Diabetol 54: 1091-1099, 2017.

20. Chuengsamarn S, Rattanamongkolgul S, Sittithumcharee G and Jirawatnotai S: Association of serum high-sensitivity C-reactive protein with metabolic control and diabetic chronic vascular complications in patients with type 2 diabetes. Diabetes Metab Syndr 11: 103-108, 2017.

21. Li X, Wu TT, Chen J and Qiu W: Elevated expression levels of serum insulin-like growth factor-1, tumor necrosis factor- $\alpha$ and vascular endothelial growth factor 165 might exacerbate type 2 diabetic nephropathy. J Diabetes Investig 8: 108-114, 2017.

22. Murai T, Takebe N, Nagasawa K, Todate Y, Nakagawa R, Nakano R, Hangai M, Hasegawa Y, Takahashi Y, Yoshioka K, et al: Association of epicardial adipose tissue with serum level of cystatin C in type 2 diabetes. PLoS One 12: e0184723, 2017.

23. Silva-E-Oliveira J, Amélio PM, Abranches ILL, Damasceno DD and Furtado F: Heart rate variability based on risk stratification for type 2 diabetes mellitus. Einstein (Sao Paulo) 15: 141-147, 2017.

24. Bhavsar NA, Appel LJ, Kusek JW, Contreras G, Bakris G, Coresh J and Astor BC; AASK Study Group: Comparison of measured GFR, serum creatinine, cystatin C, and beta-trace protein to predict ESRD in African Americans with hypertensive CKD. Am J Kidney Dis 58: 886-893, 2011.

25. Sun W, Tadmori I, Yang L, Delgado M and Ganea D: Vasoactive intestinal peptide (VIP) inhibits TGF-betal production in murine macrophages. J Neuroimmunol 107: 88-99, 2000. 
26. Menzies JR, McKee R and Corbett AD: Differential alterations in tachykinin NK2 receptors in isolated colonic circular smooth muscle in inflammatory bowel disease and idiopathic chronic constipation. Regul Pept 99: 151-156, 2001.

27. Grover M, Farrugia G, Lurken MS, Bernard CE, FaussonePellegrini MS, Smyrk TC, Parkman HP, Abell TL, Snape WJ, Hasler WL, et al: NIDDK Gastroparesis Clinical Research Consortium: Cellular changes in diabetic and idiopathic gastroparesis. Gastroenterology 140: 1575-85.e8, 2011.
28. Iwasaki H, Kajimura M, Osawa S, Kanaoka S, Furuta T, Ikuma $\mathrm{M}$ and Hishida A: A deficiency of gastric interstitial cells of Cajal accompanied by decreased expression of neuronal nitric oxide synthase and substance $\mathrm{P}$ in patients with type 2 diabetes mellitus. J Gastroenterol 41: 1076-1087, 2006.

c) (i) $(\Theta)$ This work is licensed under a Creative Commons c) Attribution-NonCommercial-NoDerivatives 4.0 International (CC BY-NC-ND 4.0) License. 